\title{
Similarities and Variabilities in Ten Cassava Germplasms from International Institute of Tropical Agriculture Onne Rivers State Nigeria
}

\author{
Cosmas Chidiebere Alamanjo ${ }^{\text {a*, Julian Osuji }}$, Isaiah Korede Alabi ${ }^{\mathrm{c}}$, Chizobam Iheoma Chizea ${ }^{\mathrm{a}}$ \\ ${ }^{a}$ Department of Agricultural Technology, Federal College of Forestry Jos Plateau State Nigeria. \\ ${ }^{b}$ Department of Plant Science and Biotechnology, University of Port Harcourt, Rivers State Nigeria. \\ ${ }^{c}$ Department of Agricultural Extension and Management, Federal College of Forestry Jos Plateau State \\ Nigeria.
}

*Corresponding Author: C. C. Alamanjo, Department of Agricultural Technology, Federal College of Forestry Jos Plateau State Nigeria.

\begin{abstract}
The quest to establish cassava cultivars with increased yield, pest and drought resistance has led to the establishment of several cassava germplasms but with little or no independent study on these germplasms. Hence, we employed basic morphological and anatomical protocol to ascertain the similarities and variabilities among 10 cassava germplasms and their potentials for yield, pest and drought resistance. Cassava germplasms were grown in soil-filled polypots, maintained at $50 \%$ field capacity and parameters like plant height, leaf area, petiole length, petiole insertion type, lobe margins, nature of cuticles, number of vasculatures in stems and petioles, presence/absence of trichomes in midribs and estimated area of vascular bundles were measured at 45 days after planting. Data collected were subjected to descriptive statistics and petiole insertion type, reticulate venation, lobe margin and number vasculatures in stems revealed similarities among all germplasms studied, thus indicating an identical ancestral origin. Nonetheless, variations were observed in plant height, leaf area, nature of cuticles, petiole length, number of vasculatures in petiole and presencelabsence of trichomes in midrib. Germplasms like TMS 95/0289, TMS 95/0166, TMS 92/0057, TMS 91/02324 were among the top performing lines on plant height, petiole length, leaf area and number of vasculatures present in the petiole and Pearson coefficient correlation among these four parameters revealed a strong positive relationships statistically significant at $p<0.05$, thus indicating that these germplasms will contribute to breeding of cassava cultivar with improved yield capabilities, as the selection of one of these parameters will positively influence others. Germplasms like TMS 96/0166, TMS 97/0211, TMS 9/1089A and TMS 98/2101 were top performers on qualities of drought and pest resistance via the presence of trichomes, thick leaf cuticles, reduced number of petiole vasculatures and area of vascular bundles in both petioles and midribs. Thus, our results suggest a possible tradeoff between breeding for increased yield and breeding for resistance to pest and drought but an exception was revealed in germplasm TMS 96/0166, which performed relatively well for increased yield potentials, drought and pest resistance. Thus, further studies are required to relate the data from studied juvenile cassava germplasms with that of their matured field grown counterpart. Also, there is need for the identification of quantitative trait loci and understanding of the genetic basis responsible for the traits revealed in germplasm TMS 96/0166 and the variabilities observed among other germplasms.
\end{abstract}

Keywords: Cassava, germplasms, trichomes, vascular bundles, vasculatures.

\section{INTRODUCTION}

Cassava (Manihot esculenta Crantz.) is among the most important staple food crop in sub-Saharan Africa, consumed frequently by a population of more than 800 million people across this region (Lebot, 2009). Cassava is the third most important source of calories in the tropics (FAO, 2010) and the sixth most significant food crop after rice, maize, sugar cane, wheat and potato, in terms of global annual production (FAOSTAT, 2010). Cassava global annual production is approximately 291.9 million tons with Africa contributing more than 177 million tons, which is about $60.9 \%$ of global production (FAOSTAT, 2019). Added to this, Nigeria has the largest contribution to global productivity, with an annual production of about 59 million tonnes (FAOSTAT, 2019), more than 
$20 \%$ of the entire global production. In terms of value addition, Nigeria is also classed as the country with the most advanced cassava transformation in Africa, (Egesi et al., 2006). Hence, the crop is known as a vital food crop in Nigeria (Ogbe et al., 2007) and it's numerous associated products and by-products (Egesi et al., 2007) tremendously increase its potential for the export market.

Based on this premise, few researchers (Nweke, 2004; Egesi et al., 2007; Raphael, 2008) have tagged cassava to be among the vital crops for food security and poverty alleviation. Among others, this is due to its adaptability to poor soils, drought tolerant, low input cost and its tendency to yield where other staple crops struggle for survival. Nonetheless, average yield for cassava in Africa still remain as low as approximately 8.8 tons/ha against its potential yield estimated to be as high as 80 tons/ha (FAOSTAT, 2015) and this is mainly attributed to constrains from the combination of biotic and abiotic factors. The quest to bridge this gap has led several research (Beck, 1982; Jennings, 1994; Hillocks and Jennings, 2003; Kawano 2003; Phillips \& Wolf 2005; Okogbenin et al., 2012) on breeding of various cultivars of cassava with moderate to significant resistant to biotic and abiotic stresses. Added to this, the International Institute of Tropical Agriculture (IITA) has contributed enormously to the release and dissemination of several cassava germplasms both for regional and national breeding programs across the African continent (Manyong et al., 2000). Yet, there has not been an independent morphological and anatomical study on most of these cassava germplasms, irrespective of their enormous potentials as regards to genetic resources needed for breeding of cassava cultivars with long lasting adaptability to biotic and abiotic factors. Based on this premise, this study aimed to carry out a line of enquiry on the morphological and anatomical similarities and variabilities in ten cassava germplasms, so as to identify germplasms with great yield potentials, resistance to biotic and abiotic factors.

\section{MATERials AND Method}

\subsection{Description of Study Area}

This study (morphological study) was carried out at Choba in 2008, close to the botanical garden of University of Port Harcourt while the anatomical study took place in the labouratory of Plant Science and Biotechnology department, University of Port Harcourt Choba Rivers state. Choba is a ward under Obio/Akpor LGA of Rivers State Nigeria, with a population of close to half a million people while Rivers state is among the states that constitute the South-south region, otherwise called the Niger Delta Region, situated between latitudes $4^{\circ} 45^{1} \mathrm{E}$ and $4^{\circ} 60^{1} \mathrm{E}$ and longitudes $6^{\circ} 50^{1} \mathrm{E}$ and $8^{\circ}$ $00^{1}$ E, bordered by Imo, Abia and Anambra States on the north, Atlantic Ocean on the south, Akwa Ibom State on the east, Bayelsa and Delta states on the west, with an approximate population of more than 5 million people and a tropical rainforest biomes (Rivers State Government, 2007; National Population Commission, 2006). The study area was influenced by its close proximity to a research institute that has contributed immensely to the development and dissemination of improved cassava germplasms across sub-Saharan Africa (IITA) (Manyong et al., 2000) and the presence of University of Port Harcourt, thus enabling easy collection of plant materials from IITA and the availability of university labouratory, needed for this research.

\subsection{Climate and Geological Features}

Rivers state is associated with hot monsoon climate due to its latitudinal position, characterized by heavy rainfall of about 2000 to $2500 \mathrm{~mm}$ between April to October, with high temperature all year round and a relatively constant high humidity. The relief is lowland, with an average elevation of 20$30 \mathrm{~m}$ above sea level and the geology is of alluvial sedimentary basin and basement complex. Soil is sandy or sandy loam underlie by a layer of impervious pan, with high tendency to leach, due to heavy rainfall in this area (Eludoyin et al., 2011).

\subsection{Plant Materials}

Plant materials from the following cassava germplasms TMS 97/0211, TMS 96/1089A, TMS 96/1642, TMS 91/02324, TMS 98/2101, TMS 92/00571, TMS 99/2123, TMS 94/0039, TMS 95/0289, TMS 95/0166 were collected in mid 2008, from International Institute of Tropical Agriculture (IITA), located at Onne in Rivers state Nigeria. 


\subsection{Experimental Design}

The experiment was carried out in a Completely Randomized Design (CRD) with 10 different treatments, each treatment representing a cassava germplasm and each germplasm replicated into three polypots, making it a total of thirty replicates/polypots for the entire study. Therefore, a total of 30 randomly selected cuttings of $20 \mathrm{~cm}$ length with 5-7 nodes on each (i.e. each cassava cutting per replica/polypot) were used for the study. Each polypot measuring $30 \mathrm{~cm}$ x $30 \mathrm{~cm}$ x $40 \mathrm{~cm}$ (when flat) were perforated to create a drainage holes and filled with sandy loamy soil, collected from $0-25 \mathrm{~cm}$ depth. Prior to planting, the polypot and its content was watered sufficiently and allowed to drain for about 24 hours. Considering the fact that cassava is a drought-tolerant crop (De Tafur et al., 1997), field capacity (FC) was maintained at 50\% throughout the growing season. Each cutting was prepared and planted into a polypot, at a slanting angle of $45^{\circ}$, with $10 \mathrm{~cm}$ length beneath the soil. Polypots were arranged side by side, based on the assumption that this spacing would not cause mutual shading within 45 Days after Planting (DAP). Also, positions of polypots were rotated every fortnightly, to reduce effects of possible environmental gradients. Planted cuttings were kept under natural climatic conditions and nurtured for a period of 7 weeks, in line with good cultivation practices for cassava plant (Abass et al., 2014).

\subsubsection{Morphological Study}

Morphological studies were carried out on ten cassava germplasms growing in-vivo, after 7 weeks of planting and mean data values of internode length, petiole length, leaf width, plant height, nature of leave cuticle, central leaf lobe shape and leaf blade were recorded, followed by the branching system and type of pigmentation showed by each germplasm. Morphological studies were carried out after 7 weeks to enable all the desired parameters to be fully developed and also to prevent leaf senescence, which could introduce bias to the experiment. Also, the leave area for each germplasm was calculated using the millimetre graph paper method (Pandey \& Singh, 2011).

\subsubsection{Anatomical Study}

Specimens like leaves, petioles and stems were excised from individual germplasm. The explants were fixed in formaldehyde Acetic Acid for 48-72 hours, prepared with the combination of 1 part of $40 \%$ formaldehyde, 1 part of $40 \%$ glacial acetic acid and 18 parts of $70 \%$ ethanol. The explants were rinsed severally using distilled water with two changes of $30 \%$ ethanol and dehydrated with several percentages of ethanol in the order of 30\%, 50\%, 70\%, 95\%, each for 2 hours and placed in absolute ethanol over night. The dehydrated specimens were further prepared for waxing by placing in each of the solutions containing a ratio of absolute ethanol to pure chloroform in the order of 3:1, 1:1 and 1:3 respectively, for 3 hours each, then in pure chloroforms for overnight. This was followed by addition of wax pellets $\left(60^{\circ} \mathrm{C}\right.$ melting points) to specimens and the wax was melted using vials. The vials and its content were kept in room temperature for 24 hours and then placed in a hot plate for 48 hours in order to complete infiltration process and also get rid of all the chloroform (Metacaife \& Chalk, 1979).

In order to embed in the wax, the content of the vials were cast into moulds and the specimens were positioned/orientated, using needles. After the solidification of the wax, they were transferred to coldwater bath for hardening and stored for two days in a refrigerator. Sections of the specimens were made using rotatory microtome. Sections of about $10-15 \mathrm{~mm}$ thick came out as ribbons and the ribbons with its specimens were placed on clean slides smeared with a thin film of haupt albumen, allowed to dry and drops of water were added prior to mounting. The slides were placed on a hot plate at $40^{\circ} \mathrm{C}$ for about 5 minutes, to enable the ribbons to expand and were stored in an oven for overnight, at a room temperature. The slides were placed in pure xylene for 2-3minutes, then in a mixture of xylene and absolute alcohol, at the ratio of 1:1, for few minutes. The slides were then transferred to another mixture of xylene and absolute alcohol for few minutes, in the ratio of 1:3 respectively, then to absolute ethanol in the order of $95 \%, 70 \%, 50 \%$, then in distilled water for about 3 minutes each. Sections of the specimen on the slides were stained by adding drops of $1 \%$ alcian blue for 5 minutes, rinsed in water for a minute and counter stained by adding drops of $1 \%$ safranin and left for a minute (Cutler, 1978).

The sections were dehydrated by immersing in ethanol in the order of 50\%, 70\%, 90\%, $95 \%$ and then in absolute ethanol. This was followed by placing the sections in the mixture of xylene and ethanol, in the ratio of 1:3 and 1:1 respectively, then in pure xylene for few seconds and mounted in Canadian balsam. The slides were dried on hot plate at $30^{\circ} \mathrm{C}$ and the transverse sections of the stems, petiole 
Similarities and Variabilities in Ten Cassava Germplasms from International Institute of Tropical Agriculture Onne Rivers State Nigeria

and roots of each of the germplasm were examined via light microscope. (Verhertbruggen, Walker, Guillon, \& Scheller, 2017)

\subsubsection{Trichome Studies}

The trichomes on the surface of the leaf were studied by the use of light microscope. The epidermal layer of each germplasm were peeled by the use of caramel hairbrush, lightly stained with $1 \%$ safranin and viewed under light microscope. The nature of the trichome for each germplasm was studied and a free hand diagram was made from the study (Verhertbruggen et al., 2017).

\subsection{Data and Statistical Analysis}

Descriptive statistics was used to estimate the similarities and variations among the germplasms studied. Data collected were compressed into a mean value for the purpose of simplicity and statistical analyses were performed using SPSS statistical package. Pearson coefficient correlation was employed to determine the strength and type of relationships among the desired variables.

\section{RESUlts}

\subsection{Morphological Studies}

The characteristics of cassava as regards to morphology are highly variable, thus indicating high level of interspecific hybridization (Augusto \& Alves, 2002). Therefore, it is not within the purview of this research to make a detailed morphological description of these germplasms in accordance to the selected morphological and agronomic descriptors for the characterization of cassava Fukuda et al., 2010, rather this study looked into a few morphological descriptors in order to ascertain their correlations to yield potential and possible contribution to increase yield, pest and drought resistance in cassava breeding. Therefore, morphological descriptors like plant height, leaf length, leaf width, leaf area and petiole length, middle leave lobe shape, lobe margins and nature of cuticles were studied among 10 cassava germplasms and the result revealed variation and few similarities across all the germplasms studied.

Nonetheless, all the germplasms studied showed a horizontal petiole insertion type and identical internode length of $2.0 \mathrm{~cm}$, with the exception of one germplasm (TMS 96/1642) that showed higher internode length of $2.5 \mathrm{~cm}$. Also, the leaves of all the germplasms studied are simple, formed by petioles, lamina and are lobed with smooth leaf lobe margins, smooth abaxial and adaxial surfaces but smoother on the adaxial surfaces, thus indicating an identical ancestral origin. The number of lobes across germplasms varies, thereby creating variation on the leaf area of each germplasm studied. Germplasms such as TMS 96/0166, TMS 97/0211, TMS 9/1089A and TMS 98/2101 exhibited thick cuticles compared to other germplasms studied. Two types of pigmentation were observed on the petiole, i.e. petioles with red pigmentation and green pigmentation. The germplasms with redpigmented petioles consist of central leaflet that are elliptic-lanceolate to lanceolate in shape while those germplasms with petioles that are green-pigmented has a central leaflet that are ovoid. Germplasms like TMS 96/1642, TMS 91/02324, TMS 92/0057, TMS 94/0039 had single stem, thus exhibiting strong apical dominance while TMS 97/0211, TMS 96/1089A, TMS 95/0289 showed lateral branching and TMS 98/2101, TMS 99/2123, TMS 95/0166 revealed reproductive branching system. The table $1 \& 2$ below summarizes the results of leaf area, plant height, leaf length, leaf width, petiole length, antinode length, petiole pigmentation and branching system obtained from 10 cassava germplasms.

Table1. Mean leaf areas, plant height, leaf length, and leaf width of ten cassava (Manihot esculenta Crantz) germplasms.

\begin{tabular}{|c|c|c|c|c|}
\hline Germplasms & Plant height $(\mathrm{m})$ & Leaf length $(\mathrm{m})$ & Leaf width $(\mathrm{m})$ & Leaf area $(\mathrm{m})$ \\
\hline TMS 97/0211 & 0.200 & 0.115 & 0.036 & 1.12 \\
\hline TMS 96/1089A & 0.220 & 0.110 & 0.035 & 1.44 \\
\hline TMS 96/1642 & 0.300 & 0.120 & 0.037 & 1.74 \\
\hline TMS 91/02324 & 0.360 & 0.160 & 0.042 & 3.20 \\
\hline TMS 98/2101 & 0.340 & 0.138 & 0.036 & 2.48 \\
\hline TMS 92/0057 & 0.400 & 0.145 & 0.047 & 3.80 \\
\hline TMS 99/2123 & 0.360 & 0.144 & 0.040 & 2.56 \\
\hline TMS 94/0039 & 0.320 & 0.120 & 0.038 & 2.20 \\
\hline TMS 95/0289 & 0.460 & 0.168 & 0.040 & 4.64 \\
\hline TMS 95/0166 & 0.420 & 0.162 & 0.040 & 4.40 \\
\hline
\end{tabular}

International Journal of Research Studies in Agricultural Sciences (IJRSAS) 
Similarities and Variabilities in Ten Cassava Germplasms from International Institute of Tropical Agriculture Onne Rivers State Nigeria

Table2. Mean petiole length, antinode's length, petiole pigmentation type and branching system observed in ten cassavas (Manihot esculenta Crantz) germplasms.

\begin{tabular}{|c|c|c|c|c|}
\hline Germplasms & Petiole length $(\mathrm{cm})$ & Antinode's length $(\mathrm{cm})$ & Petiole Pigmentation & Branching system \\
\hline TMS 97/0211 & 13.0 & 2.0 & Green Pigmentation & Lateral \\
\hline TMS 96/1089A & 14.0 & 2.0 & Green Pigmentation & Lateral \\
\hline TMS 96/1642 & 14.5 & 2.5 & Red Pigmentation & Single stem \\
\hline TMS 91/02324 & 16.2 & 2.0 & Green Pigmentation & Single stem \\
\hline TMS 98/2101 & 16.0 & 2.0 & Red Pigmentation & Reproductive \\
\hline TMS 92/0057 & 16.8 & 2.0 & Red Pigmentation & Single stem \\
\hline TMS 99/2123 & 16.0 & 2.0 & Red Pigmentation & Reproductive \\
\hline TMS 94/0039 & 15.4 & 2.0 & Green Pigmentation & Single stem \\
\hline TMS 95/0289 & 17.2 & 2.0 & Green Pigmentation & Lateral \\
\hline TMS 95/0166 & 17.0 & 2.0 & Red Pigmentation & Reproductive \\
\hline
\end{tabular}

\subsection{Anatomical Description}

\subsubsection{Stem Anatomy}

Enormous similarities were observed in the stem of all the germplams studied. Stem anatomy of these germplasms revealed to be pentagonal in transverse cross section, having 5 furrows and 5 ridges. There is presence of epidermal layer with the absence of trichomes in all the germplasms studied and a thin layer endodermis is found to enclose the vascular bundles. The vasculature of the stem shows the arrangement of the vascular bundles with respect to the number of furrows and ridges present. The arrangement of the vascular bundle is regular while the size of the vascular bundles varies across all the germplasms studied. The Vascular bundles are collateral in nature, having phloem and xylem linked by the cambium. There is presence of distinctive Pith and well-developed parenchymatous cells in all germplasms. These cells were interspersed with the air spaces to form a characteristic pattern of pith tissues, consist of varying sizes, shapes and numbers in all the germplasms studied.

\subsubsection{Petiole Anatomy}

Petiole anatomy also revealed some level of similarities as all the germplasms studied showed petiole outlines that is circular in shape and presence of epidermal cells that are uniseriate, but with the absence of pubescent. There is presence of mono stratified starch sheath with cells that varies in size, quantity and type in all the germplasms studied. In all the petioles of germplasms studied, there is presence of cortex with collenchyma layer of cells on its outermost portion and parenchymal layer of cells on innermost portion. Endodermis is found to surround the vasculatures in which the vascular bundles are arranged. The arrangement of the vascular bundle is either circular or crescent in all the germplasms studied. The major difference observed in the petiole anatomy of all the germplasms studied is the number of vasculatures present and this variation ranges from 7 to 9 vasculatures. Nonetheless, the vascular bundles for all germplasms vary in shape, are collateral, arranged in a cylindrical manner, having phloem and xylem linked by cambium. Pith is also present and consists of well-developed parenchymatous cells that are irregularly arranged. In terms of tissue type and arrangement, the petiole anatomy of all the germplasms studied were similar to their stem anatomy, thus collaborating with the findings of Nassar et al., 2008; Graciano-Ribeiro et al., 2009 and Nassar, 2016 but differs in the number of vasculatures presence. Details of the number of vasculatures as observed in ten germplasms are seen in table 3 below.

Table3. Number of vasculatures in petioles of ten cassava (Manihot esculenta Crantz) germplasms.

\begin{tabular}{|c|c|}
\hline Germplasms & Arrangement of vascular bundles \\
\hline TMS 97/0211 & 7 \\
\hline TMS 96/1089A & 7 \\
\hline TMS 96/1642 & 8 \\
\hline TMS 91/02324 & 8 \\
\hline TMS 98/2101 & 8 \\
\hline TMS 92/0057 & 8 \\
\hline TMS 99/2123 & 7 \\
\hline TMS 94/0039 & 7 \\
\hline TMS 95/0289 & 9 \\
\hline TMS 95/0166 & 9 \\
\hline
\end{tabular}




\subsubsection{Midrib Anatomy}

The midrib is highly conspicuous and u shape in cross section of all the germplasms studied, but the curve of the shape varies among germplasms. The upper and lower epidermis is present in all germplasms, together with palisade layer and sponge mesophyll adjoined to the upper and lower epidermis respectively. There is also presence of hypodermal cells directly beneath the lower epidermal layer. Some germplasms TMS 96/0166, TMS 97/0211, TMS 9/1089A and TMS 98/2101 consist of prominent trichomes that are unicellular, unbranched and non-glandular, mostly at the centre of upper epidermal layer, directly above the collenchyma cells. Added to this, the result from midrib anatomy revealed that the germplams with trichome consist of small area of xylem, phloem, collenchyma cells beneath upper epidermal layer, compared to those germplams devoid of trichomes, which revealed numerous parenchymatous cells that extend towards the lower epidermal cells and greater number of vascular bundles with larger area of xylem and phloem. Nonetheless, the vascular bundle sheaths are collateral in all germplasms studied and are arranged in U shape.

\subsection{Pearson Coefficient Correlations among Plant Height, Petiole Length, Leaf Area and Petiole No. Of Vasculatures in Ten Cassava (Manihot Esculenta Crantz) Germplasms.}

In order to assess if measurements taken from plant height, petiole length, leaf area and number of vasculatures could be used to predict yield performance in collaboration to other research findings (Brodribb et al., 2007; Sack and Scoffoni, 2013; Koester et al., 2014), the relationships between plant height, petiole length, leaf area and number of vasculatures were investigated using Pearson productmoment correlation coefficients. Preliminary analyses were performed to ensure that there is no violation of assumptions of normality, linearity and homoscedasticity.

Test for the significance of relationships between plant height, petiole length, leaf area and number of vasculatures as seen in Table 4, revealed a strong positive relationships among these variables and all correlations were statistically significant at $\mathrm{p}<0.05$, with increased plant height strongly associated with increased petiole length, leaf area and number of vasculatures.

Table4. Correlations among measured plant height, petiole length, leaf area and petiole number of vasculatures in ten cassava (Manihot esculenta Crantz) germplasms.

\begin{tabular}{|c|c|c|c|c|c|}
\hline & & Plant height & Leaf area & Petiole length & No of vasculatures \\
\hline Plant height & Pearson Correlation & 1 & $0.954^{* *}$ & $0.975^{* *}$ & $0.779^{* *}$ \\
& Sig. (2-tailed) & & 0.000 & 0.000 & 0.000 \\
& $\mathrm{~N}$ & 10 & 10 & 10 & 10 \\
\hline Leaf area & Pearson Correlation & $0.95^{* *}$ & 1 & $0.937^{* *}$ & $0.835^{* *}$ \\
& Sig. (2-tailed) & 0.000 & & 0.000 & 0.003 \\
& $\mathrm{~N}$ & 10 & 10 & 10 & 10 \\
\hline Petiole length & Pearson Correlation & $0.975^{* *}$ & $0.937^{* *}$ & 1 & $0.715^{*}$ \\
& Sig. (2-tailed) & 0.000 & 0.000 & & 0.02 \\
& $\mathrm{~N}$ & 10 & 10 & 10 & 10 \\
\hline No of & Pearson Correlation & $0.779^{* *}$ & $0.835^{* *}$ & $0.715^{*}$ & 1 \\
vasculatures & Sig. (2-tailed) & 0.008 & 0.003 & 0.020 & 10 \\
\hline & $\mathrm{N}$ & 10 & 10 & 10 & \\
\hline
\end{tabular}

**Correlation is significant at the 0.01 level (2-tailed).

*Correlation is significant at the 0.05 level (2-tailed).

\section{DISCUSSION}

Morphological and anatomical features like petiole insertion type, petiole length, petiole pigmentation, leaf venation, branching system, composition of stem and petiole anatomy including the arrangement of vascular bundles showed that the cassava germplasms studied are from common mesophytic ancestral origin with highly evolved characteristics of a dicot and this aligns with the report of Nassar, in 1995. Added to this, cassava forms the basis of food security for enormous proportion of Sub-Saharan Africa. Yet, average yield of cassava in Africa still remain as low as approximately 8.8 tons/ha against its potential yield estimated to be as high as 80 tons/ha and this is highly attributed to constrains from the combination of biotic and abiotic factors (FAOSTAT, 2015). The quest to bridge this gap has led to the release of several cassava germplasms by International Institute of Tropical Agriculture, with adequate genetic resources needed to breed cassava cultivars 
with improved yield and moderate to significant resistant to both biotic and abiotic stresses (Manyong et al., 2000). Mathan et al., 2016 in their review titled "Enhancing crop yield by optimizing plant developmental features", revealed that the overall performance of crop plants is strongly dependent on several developmental features, with reference to the overall plant architecture, leaf features and vasculature architecture, as these features direct mobilization of photosynthates from source to sink and are crucial for efficient partitioning of photoassimilated carbon, which dictates crop performance and yield.

In collaboration to these, leaf area growth in plant has also been reported to determine the level of light interception, which is a crucial parameter in determining plant productivity (Koester et al., 2014) via photosynthesis. Also, plant vasculature has been reported to contribute to the performance of plant, via provision of mechanical strength and serving as a medium for the transport of minerals, water and photosynthates (Brodribb et al., 2007; Sack and Scoffoni, 2013), while Nukanine et al., in 2002 reported a negative significant relationship between high trichome intensity and the level of cassava leaf damage by green spider mite, through mechanical disturbance of insect movement and feeding. Added to this, Dehgan in1982 reported a reduction in number of vasculatures in Jatropha traits, which is attributed to evolutionary advancement that corresponds to its adaptation to the arid climates of Central America and Africa while Fahn in 1986 reported that the presence of trichomes and thick cuticles on leaves are strongly related to minimizing water loss in dry environments. In retrospect to these facts, the knowledge of morphological descriptors like plant height, petiole length, leaf area and nature of cuticle of these germplasms, coupled with their stem, petiole and midrib anatomy, as regards to the number of vasculatures and presence/absence of trichomes, will play a vital role in the identification of cassava germplasms with increased yield potentials, resistance biotic and abiotic stress.

Therefore, in the present study, a simple morphological and anatomical study was employed to characterize the similarities and variations in 10 cassava germplasms, as regards to the aforementioned parameters and measurements obtained after 45 days of planting depicts the germplasms with potentials for better yield at later stages of development, coupled with the potentials for drought and pest resistance. The morphological study in all germplasms revealed couple of similarities like horizontal insertion of petiole, reticulate venation in leaves and internode length of $2.0 \mathrm{~cm}$, apart from germplasm TMS 96/1642, that exhibited $2.5 \mathrm{~cm}$ internode length. Nonetheless, variations were observed in morphological descriptors like petiole length, petiole pigmentation, branching system, leaf length, leaf width, nature of leaf cuticle and number of leaf lobes in each germplasm studied, which in turn led to variation in leaf area. In petiole anatomy, variations were observed in the arrangement of vascular bundles, also known as number of vasculatures and this variation ranges from 7-9 vasculatures.

In table $1 \& 3$, germplasms like TMS 95/0289, TMS 95/0166, TMS 92/0057, TMS 91/02324 were consistently among the top performing lines, as regards to plant height, petiole length, leaf area and number of vasculatures present in the petiole. Thus we subjected these parameters to Pearson coefficient correlation in order to understand the level of relations among these parameters (plant height, petiole length, leaf area and number of vasculatures in petiole). Test for the significance of relationships between plant height, petiole length, leaf area and number of vasculatures in petiole, as seen in Table 4 revealed a strong positive relationships among these variables and all correlations were statistically significant at $\mathrm{p}<0.05$. Thus indicating that these germplasms will contribute enormously to breeding of cassava cultivar with improved yield capabilities while TMS 97/0211 and TMS 96/1089A will perform relatively poor, as regards to breeding of cassava cultivar with improved yield capabilities. In midrib anatomy, germplasms were classified based on the presence and absence of trichomes and out of ten cassava germplasms studied, four germplasms (TMS 96/0166, TMS 97/0211, TMS 9/1089A and TMS 98/2101) revealed presence of unicellular unbranched trichomes, which varies in size, length and density, thus collaborating with the report of Metacalfe and Chalk in1979. It is interesting to note that these germplams with the presence of trichomes, also exhibited thick leaf cuticles, reduced number of vasculatures and a small area of xylem, phloem and collenchyma cells located beneath upper epidermal layer when compared to those without trichomes. Hence, we suggest that these germplasms (TMS 96/0166, TMS 97/0211, TMS 9/1089A and TMS 98/2101) will serve as an embodiment of genetic resources for breeding of cassava cultivar with improved drought and pest resistance, as these features collaborates with the findings of Nukanine $e t$ 
al., 2002, Dehgan 1982 and Fahn 1986, on pest and drought resistance in Euphorbiaceae plant family.

The significant positive correlations observed among plant height, petiole length, leaf area and number of vasculatures in petiole therefore suggest that selection for any of these given traits could contribute enormously to improved yield but may be detrimental to traits like resistance to pest and drought. Thus, our results however suggest a possible tradeoff between breeding for increased yield and breeding for resistance to pest and drought. Nonetheless, it is interesting to note that we observed an exception in germplasm TMS 96/0166, which not only performed relatively well for improved yield potentials but was among the top performers, as regards to the attributes of drought and pest resistance.

\section{CONCLUSION}

Characterization of cassava germplasms as regards to morphology and anatomy, are highly variable due to high level of interspecific hybridization. Nonetheless, majority of morphological and anatomical studies has focused on cassava cultivars, hence to some extent, their similarities and variabilities have been established. Moreover, morphological and anatomical traits of numerous cassava germplasms, which has the tendency to produce data that could contribute immensely to the release of new cassava cultivars with desirable characteristics, are yet to be established. Thus, the basic morphological and anatomical studies presented in this paper identifies these similarities and variabilities in ten cassava germplasms and their potentials, as regards to improved yield, pest and drought resistance were established. Considerable amount of morphological similarities were observed in parameters like petiole insertion type, leaf venation system, antinode's length and lobe margins, thus indicating common ancestral origin in all the germplasms studied. The study also showed that cassava germplasms like TMS 95/0289, TMS 95/0166, TMS 92/0057, TMS 91/02324 were consistently among the top performing lines, as regards to plant height, petiole length, leaf area and number of vasculatures present in the petiole. Also, the study through Pearson Coefficient Correlation revealed strong positive relationships among these variables and all correlations were statistically significant at $p<0.05$, thus indicating that these germplasms will contribute enormously to breeding of cassava cultivar with improved yield capabilities and that the selection of one of these parameters will positively influence others. Nonetheless, germplasms like TMS 97/0211, TMS 9/1089A and TMS 98/2101, which performed relatively poor on attributes required for improved yield were among the top performers on attributes required for pest and drought resistance, thus suggesting a possible tradeoff between breeding for improved yield and breeding for pest and drought resistance. Exception to this was revealed in TMS 96/0166, which performed relatively well for both the attributes required for improved yield, pest and drought resistance.

Therefore, the present study has provided invaluable data on the morphology and anatomical similarities and variabilities in ten cassava germplasms and it is believed that the data provided here will help to fill the gap on the hitherto scanty information available on the potentials of these germplasms, as regards to yield, pest and drought resistance. However, further studies are required to relate the data from studied juvenile cassava germplasms with that of their matured field grown counterpart. Also, there is need for the identification of quantitative trait loci and understanding of the genetic basis responsible for the desired traits revealed in germplasm TMS 96/0166 and the variabilities observed among other germplasms.

\section{ACKNOWLEDGMENT}

The authors sincerely acknowledge the management of International Institute of Tropical Agriculture Onne Rivers State, for the provision of plant materials required for this research. Also, we are thankful to the department of Plant Science and Biotechnology University of Port Harcourt, for the availability of labouratory equipment needed for the course of this research. Thanks are due to Dr. Josephine Agbogbua for her support, supervision and proof reading the manuscripts and finally to God Almighty for his grace.

\section{REFERENCES}

[1] Abass, A. B., Towo, E., Mukuka, I., Ranaivoson, R., Tarawali, G. \& Kanju, E. (2014). Growing cassava: A training manual from production to postharvest. IITA, Ibadan, Nigeria.

[2] Augusto, A., \& Alves, C. (2002). Cassava Botany and Physiology. 67-89. 
[3] Beck, B. (1982). "Historical perspectives of cassava breeding in Africa", in Workshop on Root Crops in Eastern Africa, ed S. K. Hahn (Kigali: IDRC), 298-300.

[4] Brodribb, T. J., Feild, T. S. \& Jordan, G. J. (2007). Leaf maximum photosynthetic rate and venation are linked by hydraulics. Plant Physiol. 144, 1890-1898.

[5] Cutler, D.F. (1978). Applied plant anatomy. Longman Group Limited, London.

[6] Dehgan, B. (1982). Comparative anatomy of the petiole and infrageneric relationships in Jatropha (Euphorbiaceae). Am. J. Bot. 69: 1283-1295. http://dx.doi.org/10.2307/2442753

[7] De Tafur, S.M., El-Sharkawy, M.A., Cadavid, L.F. (1997). Response of cassava (Manihot esculenta Crantz) to water stress and fertilization. Photosynthetica, 34, 233-239.

[8] Egesi, C., Mbanaso, E., Ogbe, F., Okogbenin, E. \& Fregene, M. (2006). Development of cassava varieties with high value root quality through induced mutations and marker-aided breeding. NRCRI, Umudike Annual Report 2006. :2-6

[9] Egesi, C., Okogbenin, E., Mbanaso, E. \& Fregene, M. (2007). Induced mutations and marker-aided breeding for the improvement of root quality traits in cassava. NRCRI, Umudike Annual Report 2007. :22-23.

[10] Eludoyin, O. S., Wokocha, C. C. \& Ayolagha, G. (2011). GIS Assessment of Land Use and Land Cover Changes in OBIO / AKPOR L . G . A ., Rivers State , Nigeria. 3(4), 307-313.

[11] Fahn, A. (1986). Structural and functional properties of trichomes of xeromorphic leaves. Ann. Bot. (Lond.) 57: 631-637.

[12] FAO, (2010). Why Cassava? Available online: http://www.fao.org/ag/AGP/agpc/gcds/ index_en.html (accessed on 9 July 2010).

[13] FAOSTAT (2010). Food and Agricultural Commodities Production; Available online: http://faostat.fao.org/ (accessed on 1 April 2010).

[14] FAOSTAT (2015). Statistical Database of the Food and Agriculture Organization of the United Nations. Available online at: http://faostat.fao.org (Accessed on 12 April 2016).

[15] FAOSTAT (2019). Statistical Database of the Food and Agriculture Organization of the United Nations on Crop Production. Available online at: http://www.fao.org/faostat/en/\#data. (Accessed on 9 October 2019).

[16] Fukuda, W.M.G., Guevara, C.L., Kawuki, R. \& Ferguson, M.E. (2010). Selected morphological and agronomic descriptors for the characterization of cassava. International Institute of Tropical Agriculture (IITA), Ibadan, Nigeria. $19 \mathrm{pp}$.

[17] Graciano-Ribeiro D, Hashimoto DYC, Nogueira LC, Teodoro D., Miranda, S. F. \& Nassar, N. M. A. (2009). Internal phloem in an interspecific hybrid of cassava, an indicator of breeding value for drought resistance. Genet. Mol. Res. 8: 1139-1146. http://dx.doi.org/10.4238/vol8-3gmr629

[18] Hillocks, R. \& Jennings, D. (2003). Cassava brown streak disease: a review of present knowledge and research needs. Pest Sci. 49, 225-234. doi: 10.1080/0967087031000101061

[19] Horton, P. (2000). Prospects for crop improvement through the genetic manipulation of photosynthesis: morphological and biochemical aspects of light capture. J. Exp. Bot. 51, 475-485.

[20] Jennings, D. (1994). Breeding for resistance to African cassava mosaic geminivirus in East Africa. Trop. Sci. 34, 110-122.

[21] Kawano, K. (2003). Thirty years of cassava breeding for productivity. Biological and social factors for success. Crop Science 43, 1325-1335.

[22] Koester, R. P., Skoneczka, J. A., Cary, T. R., Diers, B. W. \& Ainsworth, E. A. (2014). Historical gains in soybean (Glycine max Merr.) seed yield are driven by linear increases in light interception, energy conversion, and partitioning efficiencies. J. Exp. Bot. 65, 3311-3321. doi: 10.1093/jxb/eru187

[23] Lebot, V. (2009). "Cassava," in Tropical Root and Tuber Crops: Cassava, Sweet Potato, Yams and Aroids, ed J. Artherton (Cambridge, MA: CABI), 3-85.

[24] Manyong, V. M., Makinde, K. O., Bokanga, M. \& Whyte, J. (2000). The contribution of IITA-improved cassava to food security in sub-Saharan Africa : an impact study.

[25] Mathan, J., Bhattacharya, J. \& Ranjan, A. (2016). Enhancing crop yield by optimizing plant developmental features. 3283-3294. https://doi.org/10.1242/dev.134072

[26] Metacaife, C.R. \& Chalk, L. (1979). Anatomy of the Dicotyledons; Vol. 1 2nd Ed, Clarendon press, Oxford.

[27] Meyer, R. S. \& Purugganan, M. D. (2013). Evolution of crop species: genetics of domestication and diversification. Nat. Rev. Genet. 14, 840-852.

[28] Nassar N.M.A. (1995). Development and selection for apomixis in cassava, Manihot esculenta Crantz. Can. J. Plant Sci. 74: 857-858. 
[29] Nassar, N. M. A. (2016). Comparative petiole anatomy of cassava ( Manihot ) species. 15(1), 1-13.

[30] Nassar NMA, Graciano-Ribeiro D, Fernandes SDC and Araujo PC (2008). Anatomical alterations due to polyploidy in cassava, Manihot esculenta Crantz. Genet. Mol. Res. 7: 276-283. http://dx.doi.org/10.4238/vol7-2gmr399

[31] National Population Commission (2006). Legal notice on publication of 2006 census final results. Federal Republic of Nigeria Official Gazette, Abuja. 2(96):1-42.

[32] Nukanine, E. N., Dixon, A. G. O., Hassan, A. T. \& Zalom, F. G. (2002). Relationships between leaf trichome characteristics and field resistance to cassava green mite, Mononychellus tanajoa (Bondar)," Systematic and Applied Acarology 7(1), 77-90. https://doi.org/10.11158/saa.7.1.9

[33] Nweke F. I. (2004). Cassava. A cash crop in Africa. A Collaborative Study of Cassava in Africa, working paper. No. 14

[34] Ogbe, F.O., J.K.U. Emehute \& J. Legg. (2007). Screening of cassava varieties for whitefly populations. In: NRCRI Annual Report 2007:30-33.

[35] Okogbenin, E., Egesi, C., Olasanmi, B., Ogundapo, O., Kahya, S., Hurtado, P., Marin, J., Akinbo, O., Mba, C., Gomez, H., de Vicente, C., Baiyeri, S., Uguru, M., Ewa, F. \& Fregene, M. (2012). Molecular marker analysis and validation of resistance to cassava mosaic disease in elite cassava genotypes in Nigeria. Crop Sci. 52, 2576-2586. doi: 10.2135/cropsci2011.11.0586

[36] Pallioti, A., Bongi, G. \& Rocchi, P. (1994). Peltate trichomes effects on photosynthetic gas exchange of Olea europaea L. leaves. Plant Physiol. 13: 35-44.

[37] Pandey, S. K. \& Singh, H. (2011). A Simple , Cost-Effective Method for Leaf Area Estimation. 2011. https://doi.org/10.1155/2011/658240

[38] Phillips, S. L. \& Wolfe, M. S. (2005). Evolutionary plant breeding for low input systems. Journal of Agricultural Science, Cambridge 143, 245-254.

[39] Raphael, I. O. (2008). Technical efficiency of cassava farmers in south eastern Nigeria: Stochastic frontier approach. J. Agric. Sci. 3, 152-156.

[40] Rivers State Government. (2007). People of Rivers State. Retrieved from 2007 Dairy of Rivers State Government House, Port Harcourt, Rivers state Nigeria.

[41] Robinson, S. A. \& Osmond, C. B. (1994). Internal gradients of chlorophyll and carotenoid pigments in relation to photoprotection in thick leaves of plants with crassulacean acid metabolism. Funct. Plant Biol. 21: 497-506.

[42] Sack, L. \& Scoffoni, C. (2013). Leaf venation: structure, function, development, evolution, ecology and applications in the past, present and future. New Phytol. 198, 983-1000.

[43] Verhertbruggen, Y., Walker, J. L., Guillon, F. \& Scheller, H. V. (2017). A Comparative Study of Sample Preparation for Staining and Immunodetection of Plant Cell Walls by Light Microscopy. 8(August), 1-17. https://doi.org/10.3389/fpls.2017.01505

Citation: Cosmas Chidiebere Alamanjo, et.al, "Similarities and Variabilities in Ten Cassava Germplasms from International Institute of Tropical Agriculture Onne Rivers State Nigeria” International Journal of Research Studies in Agricultural Sciences (IJRSAS), 2019; 5(12), pp. 8-17, http://dx.doi.org/10.20431/24546224.0512002

Copyright: (C) 2019 Authors. This is an open-access article distributed under the terms of the Creative Commons Attribution License, which permits unrestricted use, distribution, and reproduction in any medium, provided the original author and source are credited. 